EESTI NSV TEADUSTE AKADEEMIA TOIMETISED. 20. KÖIDE

KEEMIA * GEOLOOFIA. 1971, NR. 3

ИЗВЕСТИЯ АКАДЕМИИ НАУК ЭСТОНСКОН ССР. ТОМ 20

ХимИя - ГЕОЛОГИЯ. 1971, № 3

УДК 542.952

AHНЕ OРАВ, О. ЭИЗЕН

\title{
ОБ ИЗОМЕРИЗАЦИИ НОРМАЛЬНЫХ ОЛЕФИНОВ
}

Вопрос об изомеризации н-юлефинов с одновременным определением индивидуальногс состава изомеризата изучен сравнительно мало, хотя он имеет значение при выработке методов анализа олефинов в углеводородных смесях [1'].

\section{Экспериментальная часть}

Изомеризация $\boldsymbol{H}$-олефинов на бромистом алюминии проводилась аналогично изомеризации октана по Петрову [2]. Реакция проходила в закрытой колбе при комнатной температуре. Для перемешивания смеси использовалась установка $L E-203$ фирмы «Лабор».

Опыты по изомеризации на силикагеле проводились в стеклянной колонке длиной 280 мм и внутренним диаметром 10 мм. Для анализа продуктов изомеризации применялся газовый хроматограф «Хром-2» с пламенно-ионизационным детектором и капиллярной колонкой (длина 80 , внутренний диаметр $0,25 \mathrm{Mм})$.

В присутствии бромистого алюминия проводилось три опыта изомеризации при условиях, изложенных в табл. 1. Силикагели КСК, КСМ,

Таблица 1

Условия опыта

\begin{tabular}{c|c|c|c}
\hline \multirow{3}{*}{ Опыт } & $\begin{array}{c}\text { Количество } \\
\text { начальной } \\
\text { смеси, } м л\end{array}$ & $\begin{array}{c}\text { Количество } \\
\mathrm{AlBr}_{3}, \\
2\end{array}$ & Время \\
& изомеризации \\
\hline
\end{tabular}

$\begin{array}{llll}1 & 15 & 5,0 & 12,5 \text { ч со встряхиванием } \\ 2 & 15 & 4,2 & 5 \text { мин } \\ 3 & 15 & 1,0 & 2 \text { мин }\end{array}$

применяемые в опытах изомеризации олефинов, нагревались в течение 6 ч при $60^{\circ}$ и 24 ч при $150^{\circ}$ С. Опыты проводились с чистым 1-октеном $(100 \%)$ и с олефиновыми смесями при комнатной температуре и при $40^{\circ}$; продолжительность - от одного до шести дней.

\section{Результаты}

Нормальные олефины изомеризовались в присутствии бромистого алюминия очень легко. В опытах 1 и 2 происходила также полимеризация веществ. 
Таблица 2

Результаты изомеризации смесей $H$-октенов в присутствии бромистого алюминия

\begin{tabular}{|c|c|c|c|c|c|}
\hline \multirow{2}{*}{ 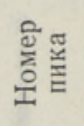 } & \multirow[t]{2}{*}{ Вещество } & \multirow{2}{*}{$\begin{array}{c}\text { Состав } \\
\text { начальной } \\
\text { смеси, } \%\end{array}$} & \multicolumn{3}{|c|}{$\begin{array}{c}\text { Состав продуктов изоме- } \\
\text { ризации, \% }\end{array}$} \\
\hline & & & Опыт 1 & Опыт 2 & Опыт 3 \\
\hline \multicolumn{2}{|c|}{1 н-Бутан } & - & 2,54 & 0.63 & - \\
\hline & Бутены & - & 2,35 & 0,81 & - \\
\hline & $\mathrm{H}$-Пентан & - & 5,42 & 1,93 & - \\
\hline $5 ; 6$ & Пентены & -1 & 5,05 & 2,70 & - \\
\hline \multirow{3}{*}{$\begin{array}{l}7 \\
8 \\
9\end{array}$} & $H$-Гексан & - & 8,34 & 3,46 & - \\
\hline & Гексен-1 & - & 6,28 & 2,27 & - \\
\hline & транс-Гексен-2 & - & 2,48 & 1,78 & - \\
\hline \multirow{2}{*}{$\begin{array}{l}10 \\
11\end{array}$} & цис-Гексен-2 & - & 4.54 & 1,23 & - \\
\hline & $\mu$-Гептан & - & 9,87 & 3,32 & - \\
\hline 12 & $\left\{\begin{array}{l}\text { Гептен-1 } \\
\text { транс-Гептен-3 }\end{array}\right.$ & - & 1,91 & 1,58 & - \\
\hline \multirow{5}{*}{$\begin{array}{l}13 \\
14 \\
15 \\
16 \\
17\end{array}$} & $\begin{array}{c}\text { (транс-1 ептен- } \\
\text { цис-Гептен-3 }\end{array}$ & - & 2,92 & 2,54 & - \\
\hline & транс-Гептен-2 & - & 1,91 & 1,58 & - \\
\hline & цис-Гептен-2 & - & 1,97 & 2,33 & - \\
\hline & H-Октан & - & 18,20 & 9,10 & - \\
\hline & транс-Октен-4 & 5,03 & 0,86 & 8,40 & 8,14 \\
\hline 18 & $\left\{\begin{array}{l}\text { транс-Октен-3 } \\
\text { Октен-1 }\end{array}\right.$ & 50,7 & 6,29 & 15,50 & 26,60 \\
\hline 19 & $\left\{\begin{array}{l}\text { иис-Октен-4 } \\
\text { иис-Октен-3 }\end{array}\right.$ & 9,44 & 4,55 & 9,59 & 15,09 \\
\hline \multirow{2}{*}{$\begin{array}{l}20 \\
21\end{array}$} & транс-Октен-2 & 19,60 & 4,71 & 5,94 & 31,12 \\
\hline & $\begin{array}{l}\text { Неидентифици- } \\
\text { ровано }\end{array}$ & - & 4,35 & - & - \\
\hline 22 & цис-Октен-2 & 15,23 & 1,16 & 4,31 & 19,05 \\
\hline & $\begin{array}{l}\text { Сумма } н \text {-парафи- } \\
\text { нов } \\
\text { Сумма } н \text {-олефинов }\end{array}$ & $10 \overline{000}$ & $\begin{array}{l}44,37 \\
51,28\end{array}$ & $\begin{array}{l}18,44 \\
81,56\end{array}$ & 100,00 \\
\hline
\end{tabular}

В табл. 2 приводятся составы начальной смеси и продуктов изомеризации в неполимеризованной части, на рисунке - хроматограммы продуктов изомеризации в опытах 1 и 2 . Все нормальные олефины от $\mathrm{C}_{4}-\mathrm{C}_{8}$

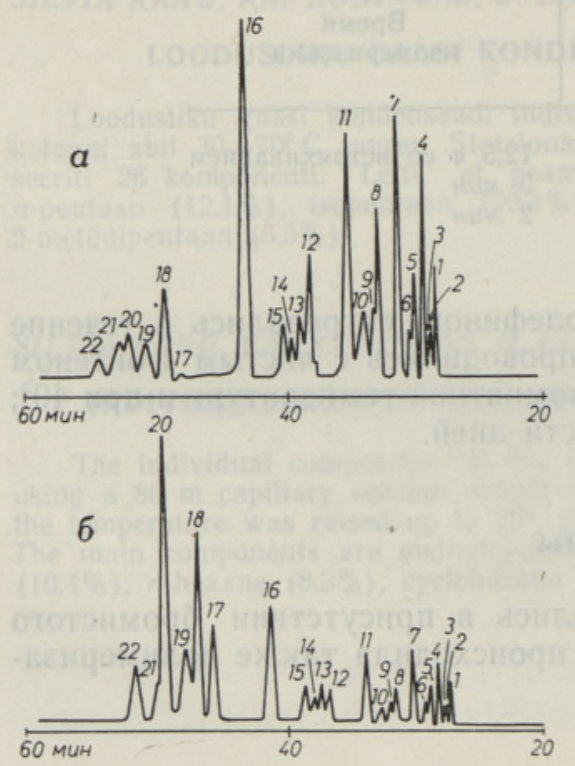

и $\boldsymbol{H}$-парафины на хроматограммах идентифицированы с помощью индексов Ковача [3].

В результате третьего опыта изменились только соотношения изомерных октенов в пробе, количество 1-октена уменьшилось в два раза и возросло количество транс-октена-2.

Из изомерных октенов, как видно из табл. 2, в присутствии бромистого алюминия можно получить смеси более легких олефинов.

Хроматограммы продуктов изомеризации сме-

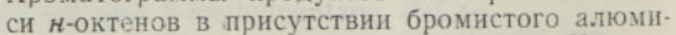
ния. Капиллярная колонка длиной $80 \mathrm{M}$ こ ПЭГ-4000, температура колонки $63^{\circ} \mathrm{C}$, вхсдное давление $1,63 \kappa 2 / C \mathrm{~s}^{2}$. $a$ - опыт $1 ; 6$ - опыт 2 . 
Таблица :

Результаты изомеризации октена-1 (100\%) на силикагелях

\begin{tabular}{|c|c|c|c|c|c|c|c|}
\hline \multirow[b]{2}{*}{$\begin{array}{c}\text { Силика- } \\
\text { гель }\end{array}$} & \multirow{2}{*}{$\begin{array}{c}\text { Весовое } \\
\text { соотно- } \\
\text { шение } \\
\text { силикагеля и } \\
\text { октена-1 }\end{array}$} & \multirow{2}{*}{$\begin{array}{l}\text { Фракция } \\
\text { силика- } \\
\text { геля, мм }\end{array}$} & \multirow{2}{*}{$\begin{array}{l}\text { Tемпе- } \\
\text { ратура } \\
\text { опыта, } \\
{ }^{\circ} \mathrm{C}\end{array}$} & \multirow{2}{*}{$\begin{array}{l}\text { Продол- } \\
\text { житель- } \\
\text { ность } \\
\text { опыта, } и\end{array}$} & \multicolumn{3}{|c|}{ Продукты изомеризации, \% } \\
\hline & & & & & $\begin{array}{l}\text { транс- } \\
\text { октен-2 }\end{array}$ & $\begin{array}{c}\text { циис- } \\
\text { октен-2 }\end{array}$ & октен-1 \\
\hline $\begin{array}{l}\mathrm{KCK} \\
\mathrm{KCM}\end{array}$ & $\begin{array}{l}3: 1 \\
3: 1\end{array}$ & $\begin{array}{c}0,053-0,315 \\
0,25-0,19\end{array}$ & $\begin{array}{l}40 \\
40\end{array}$ & $\begin{array}{l}20 \\
20\end{array}$ & $\begin{array}{r}9,22 \\
24,96\end{array}$ & $\begin{array}{l}10,48 \\
19,18\end{array}$ & $\begin{array}{l}80,30 \\
55,86\end{array}$ \\
\hline
\end{tabular}

Таблица 4

Результаты изомеризации октенов и ноненов на силикагеле КСМ

Опыты по изучению влияния температуры на степень изомеризации олефинов показали, что при комнатной температуре октен-1, смеси изомерных октенов и изомерных ноненов не изомеризовалис , даже в течение шести дней. При $40^{\circ}$ на силикагеле КСM (см. табл. 3) изомеризовалось октена-1 44,14\%.

Степень изомеризации смесей октенов и ноненов при $40^{\circ}$ на силикагеле КСМ была различной, однако у ноненов она была более значительной (см. табл. 4).

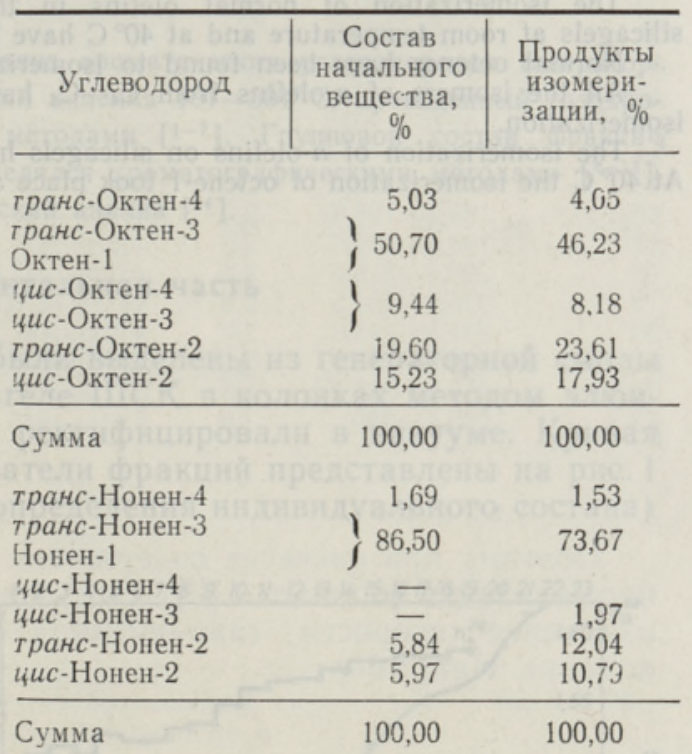

Л И ТЕРАТ У Р А

1. Эй зен О., Ку дрявцев а Л., Р анг С., Изв. АН ЭССР, Сер. физ.-матем. и техн. H., 4, 275 (1964).

2. Брянская Э. К., 3 ах аренко В. А., ПІ етров Ал. А., Нефтехимия, VI, № 5, 784 (1966).

3. Э й зен О., О р а в А., Изв. АН ЭССР, Хим. Геол., 20, № 2, 120 (1971).

Институт химии

Академии наук Эстонской ССР
Поступила в редакцию $28 /$ XII 1970 
ANNE ORAV, O. EISEN

\section{n-OLEFIINIDE ISOMERISATSIOONIST}

Uuriti n-okteenide isomerisatsiooni $\mathrm{AlBr}_{3}$ juuresolekul ja 1-okteeni ning okteenide ja noneenide isomeeride segude isomerisatsiooni silikageelil toatemperatuuris ja $40^{\circ} \mathrm{C}$ juures.

Leiti, et $\mathrm{AlBr}_{3}$ juuresolekul isomeriseeruvad $n$-olefiinid väga kergesti. Reaktsiooniproduktides identifitseeriti $25 n$-parafiini ja $n$-olefiini $\mathrm{C}_{4}-\mathrm{C}_{8}$.

$n$-olefiinide isomerisatsiooni silikageelidel toatemperatuuris ei märgatud. $40^{\circ} \mathrm{C}$ juures toimus isomerisatsioon kuni $40 \%$ ulatuses.

\section{ANNE ORAV, O. EISEN}

\section{ON THE ISOMERIZATION OF NORMAL OLEFINS}

The isomerization of normal olefins in the presence of $\mathrm{AlBr}_{3}$ and on various silicagels at room temperature and at $40^{\circ} \mathrm{C}$ have been investigated.

Normal octenes have been found to isomerize very easily in the presence of $\mathrm{AlBr}_{3}$.

All the isomers of $n$-olefins from $\mathrm{C}_{4}-\mathrm{C}_{8}$ have been identified in the products of isomerization.

The isomerization of $n$-olefins on silicagels has not been stated at room temperature. At $40^{\circ} \mathrm{C}$ the isomerization of octene- 1 took place at a rate of 40 per cent. 